ALGIMANTAS KAJACKAS, Ph.D.

E-mail: algimantas.kajackas@vgtu.lt

Faculty of Electronics

Department of Telecommunication Engineering

Vilnius Gediminas Technical University

Naugarduko 41, LT-03227 Vilnius, Lithuania

VIDAS ŽURAULIS, Ph.D. Student

E-mail: vidas.zuraulis@vgtu.It

Traffic Safety Laboratory

EDGAR SOKOLOVSKIJ, Ph.D.

E-mail: edgar.sokolovskij@vgtu.It

Faculty of Transport Engineering

Department of Automobile Transport

Vilnius Gediminas Technical University

J. Basanaviciaus 28B, LT-03224 Vilnius, Lithuania
Intelligent Transportation Systems (ITS)

Preliminary Communication

Submitted: July 16, 2014

Approved: May 27, 2015

\title{
INFLUENCE OF VANET SYSTEM ON MOVEMENT OF TRAFFIC FLOWS IN EMERGENCY SITUATIONS
}

\begin{abstract}
The paper presents Vehicular Ad Hoc Network (VANET) system based on an analysis of the movement of a motorcade in an emergency situation. This analysis seeks to answer the question: when and under what conditions Emergency Message (EM) sent by Vehicle-to-Vehicle (V2V) system reaches the final target to help in preventing of serious accidents, such as multi-vehicle collisions. The model of calculation based on the key principles of vehicle braking enables finding the time to possible collision and the residual velocity of the vehicle. In the calculations, the average values of the driver's reaction time are accepted; in addition, a sent emergency message is considered to be free of interference. Upon choosing different road and driving conditions, it is found what vehicle of the motorcade stops before the possible obstacle on emergency braking. The performance of vehicles with and without VANET system is compared.
\end{abstract}

\section{KEY WORDS}

VANET; vehicle communication; braking; emergency stop; time to collision; residual velocity;

\section{INTRODUCTION}

In scientific publications, various kinds of traffic accidents are discussed; they include collisions of vehicles [1], hitting a pedestrian [2], knocking of vehicles against obstacles and so on. To avoid knocking of the following vehicles against appearing obstacles, or stopped vehicles, the braking parameters, the adherence properties [3], the driving velocities and other factors should be taken into account. The adherence of the wheels of a vehicle with the pavement depends on the type and the quality of the latter $[4,5]$. In the research work carried out by the Department of Transportation Engineering, three key types of traffic events were singled out: non-observance of a safe distance between vehicles, head-on collisions, off-going from the road and knocking against an obstacle. In the course of research, it was found that the above-listed types of traffic events account for about $75 \%$ of all traffic accidents.

Upon striving to improve the working conditions for drivers and to reduce the accident rate, special information systems united by the joint conception - so called Intelligent Transportation Systems (ITS) are developed and improved. The essential part of ITS is Vehicular Ad Hoc Network (VANET) [6]. Vehicular ad hoc networks (VANETs) are networks in which each node is a vehicle. Such systems aim to provide communications between individual vehicles and between vehicles and nearby fixed equipment, or roadside units. The goal of VANETs is to improve the traffic safety by providing timely information to drivers and concerned authorities.

The concept of VANET is used when talking about communication technologies between vehicles and ITS infrastructure to improve, among others, road safety $[7,8]$. Vehicular networks are becoming a reality that will enable a variety of applications such as safety, traffic efficiency, and infotainment. There has been significant interest and progress in the field of VANETs 
over the past years which can provide a range of applications to improve safety, efficiency and convenience in transportation by means of Vehicle-to-Vehicle (V2V) and Vehicle-to-Infrastructure (V2I) communications [9]. Milanes et al. [10] analyze V2V communication system in which the activation of braking is based on the measurement of two variables: the distance between the vehicles and acceleration of the leading vehicle. Failure probability is checked during driving with adaptive cruise control system. Negative effects of the parasitic time delays and lags on the motorcade stability have been investigated [11].

Collective safety applications are based on the frequent exchange of short status messages, also known as beacons by the vehicles. In VANETs, which are based on IEEE 802.11p protocol $[12,13]$, beacons are broadcast periodically by each vehicle. Beacons carry the information about the vehicle, such as its position, velocity, acceleration and messages content type. According to several situations, three types of safety messages [14] are normally assigned: Information Message (IM), Warning Message (WM) and Emergency Message (EM).

The mission of IM is announcement of driving information, such as information about traffic jams on some road segments to direct the driver to the fastest and least congested road. WM should be sent to advertise an important event on the road but not immediate (critical) danger. The mission of EM is immediate danger notification. This type of messages is sent in case of accidents, very bad road condition, such as ice, fog etc.

The analysis of the published papers that failed to detect work with safety messaging issue is addressed holistically, in relation to the vehicle dynamic properties and the driver's individual properties. This paper presents a comprehensive study of VANET as a warning service system to prevent accidents by alerting drivers about accidents and dangerous road conditions. In short, this study seeks to answer the question: when and under what conditions the EM sent by V2V system reaches the final target to help in preventing serious accidents, such as multi-vehicle collisions.

This paper consists of a short review of vehicle braking, motorcade of moving vehicles and vehicle communication model used in further analysis. Emergency braking is presented by two scenarios, with and without communication system, and according to this, the calculations of time to collision and residual velocity by the vehicle number in motorcade are established.

\section{BASICS OF VEHICLE BRAKING}

The vehicle braking deceleration is an important indicator reflecting vehicle braking performance. The deceleration value is often expressed by the formula: $a=-g \mu$,

where: $g$ is the acceleration of gravity $\left(g=9.81 \mathrm{~m} / \mathrm{s}^{2}\right)$; $\mu$ is the vehicle coefficient of friction which depends on the properties of vehicle tires, road type and weather conditions.

Assuming that the deceleration remains constant during braking time $T$, the residual velocity is:

$v(t+T)=v(t)-g \mu T$,

The variation of velocity during braking time $T$ :

$\Delta v=[v(t)-v(t+T)]=g \mu T$.

By this assumption, path travelled during time T:

$$
\begin{aligned}
& X\left(t_{0}+T\right)-X\left(t_{0}\right)=\int_{t_{0}}^{t_{0}+T} v(t) d t= \\
& =\int_{t_{0}}^{t_{0}+T}\left(-g \mu t+g \mu t_{0}+v_{0}\right) d t=\left(v_{0}-\frac{1}{2} g \mu t\right) T,
\end{aligned}
$$

where $v_{0}=v\left(t_{0}\right)$ is initial velocity of the vehicle.

The stopping time $\Delta T_{s}$ during which the vehicle completely stops $\left(v\left(t_{0}+\Delta T_{s}\right)=0\right)$ in emergency braking $\left(\mu=\mu_{e}\right)$ is:

$\Delta T_{\mathrm{s}}=\frac{v\left(t_{0}\right)}{g \mu_{e}}$.

The stopping distance $\Delta X_{s}(\mu)$ is the distance run by a vehicle with initial speed $v_{0}$ after brakes run to full stopping. Theoretical stopping distance is calculated using the following formula:

$$
\begin{aligned}
& \Delta X_{s}=\left[v_{0}-\frac{g \mu_{e} \Delta T_{s}}{2}\right] \cdot \Delta T_{s}=\left[v_{0}-g \mu_{e} \frac{v_{0}}{2 g \mu_{e}}\right] \cdot \frac{v_{0}}{g \mu_{e}}= \\
& =\frac{v_{0}^{2}}{2 g \mu_{e}} .
\end{aligned}
$$

The values of stopping time $\Delta T_{s}$ and stopping distance $\Delta X_{s}$ are theoretical values established only on the basis of the laws of physics from the moment when the brakes are activated. The total stopping time and the total stopping distance are $T_{S}$ and $D_{S}$ and they are calculated from the moment when the driver notices an obstacle to the vehicle full stopping. In this time span, additional driver perception-reaction time and vehicle reaction time decreases:

$T_{\mathrm{s}}=\Delta T_{\mathrm{s}}+t_{\mathrm{re}}+t_{p r}$,

where $t_{r e}$ is time required to recognize the obstacle as a hazard; $t_{p r}$ is the pre-braking time. This is the period of time that elapses between the moment the hazard is recognized and the start of braking:

$t_{p r}=\tau_{r}+\tau_{u}+\tau_{a}+0.5 \tau_{\mathrm{s}}$,

where $\tau_{r}$ is the driver's reaction time; $\tau_{u}$ is the transfer time during the time it takes the driver to put foot on the brake pedal; $\tau_{a}$ is the brake response time; $\tau_{s}$ is the pressure build-up time [2].

The time required to recognize the obstacle as a hazard varies within the range of 0.2-0.6 s. The prebraking time of individual drivers varies within the range of 0.75-1.5 s [15]. According to other sources, the driver's reaction time is 0.6-1.2 s. The vehicle 
maximum (emergency) deceleration depends on the road type and weather conditions, on vehicle type and road conditions $[16,17]$. Depending on the vehicle weight and size as well as the road conditions (dry, wet, snowy, icy), emergency braking friction coefficients $\mu_{e}$ may vary theoretically from 1.0 to 0.1 . Some papers introduce additional vehicle safety indicator - tire condition $\varkappa=(0.1-1)$ [18], which reduces the coefficient of friction. In this paper this coefficient is used as constant for all vehicles of motorcade. Therefore, when counting driver reaction time and the response time of the brake system, the vehicle stopping distance is:

$D_{s}=v_{0}\left(t_{r e}+t_{p r}\right)+\Delta X_{s}=v_{0}\left(t_{r e}+t_{p r}\right)+\frac{v_{0}^{2}}{2 g \mu_{e} \varkappa}$.

The next important safety indicator is the distance or spacing between the following vehicles $d_{i, i+1}$. Safe following distance (safe following gap, safe inter-distance) is often defined as the minimal inter-distance to avoid a rear-end collision under unpredictable actions of the preceding vehicle. Safe following distances vary depending on what speed you are travelling at, what conditions you are driving in and what type of vehicle you are driving. In most cases, a driver in a vehicle should drive at least two seconds (sometimes three) behind the vehicle in front, in ideal conditions.

$D_{s f}=v \cdot \theta_{s}$,

where $\theta_{s}$ is the safe time gap. This time gap shall be $\theta_{s}=2-3 \mathrm{~s}$.

\section{MOTORCADE OF VEHICLES ON MOTORWAY}

Consider a platoon of vehicles $C_{i}, C_{i+1}, \ldots, C_{i+j}$, $\ldots(j=1,2, \ldots, n)$ running on the highway in a string (Figure 1). For each vehicle, the following is defined: $L_{i}$ - the $i$-th vehicle length, $x_{i}(t), v_{i}(t), a_{i}(t)$ - the position, velocity, and acceleration of the $i$-th vehicle, respectively, on the road at time $t$.

As shown in Figure 1, the spacing between the vehicles $C_{i}$ and $C_{i+1}$ is:

$$
d_{i, i+1}=x_{i}-x_{i+1}-L_{i},
$$

The total distance $D_{i, i+j}$ between vehicles $C_{i}$ and $C_{i+j}$ is expressible through the spaces between the vehicles and lengths of vehicles:
$D_{i, i+j}=x_{i}-x_{i+j}=\sum_{k=i}^{i+j-1} d_{k, k+1}+\sum_{k=i}^{i+j-1} L_{k}$.

This paper analyzes two scenarios of vehicle braking. The first scenario - as is the current practice, where vehicles are not equipped with VANET systems. The second scenario, when the vehicles are equipped with radio communication system VANET. For the analysis of emergency stop of vehicles, we chose a passive obstacle. It can be seen, but cannot send any alarm.

\section{SIMPLE V2V SYSTEM MODEL}

Relevant V2V system model contains VANET in vehicles $C_{i}, C_{i+1}, \ldots, C_{i+j}, \ldots(j=1,2, \ldots, n)$. The chosen $\mathrm{V} 2 \mathrm{~V}$ communication model is based on beacon messages. Beacon messages are broadcast periodically and inform the neighbouring vehicles of their existence. Every beacon message contains unique vehicle identifier, a time stamp, vehicle's position, velocity, acceleration. In an emergency, V2V system sends the alarm message.

Delivery latency and reliability of EM are critical performance measures of V2V system.

The message sent by vehicle $C_{i}$ to the neighboring vehicles gets to them a little later. This message delay depends on the channel bandwidth and the distance between vehicles. Research results [18] show that at short range (up to $100 \mathrm{~m}$ ) direct (without repeater) transfer takes 0.133-0.266 ms. As can be seen, the physical transmission times are quite small.

If the first communication is unsuccessful and EM is accepted on the repeated broadcasting, an additional delay appears. In VANETs based on IEEE 802.11p protocol, it conforms to beacon repetition period equal to $100 \mathrm{~ms}$. Each additional EM repetition should add a delay of $100 \mathrm{~ms}$.

The reliability of transmission of beacon messages as well as emergency messages depends on the distance between vehicles and on additional obstacles between V2V as well as on the absence (Line of Sight (LOS) conditions) or existence (NLOS conditions) of any additional obstacles between V2V stations. In NLOS conditions the receiver gets only the reflected waves and the connection is less reliable. According to [19], the reliability of successful transmission of beacon

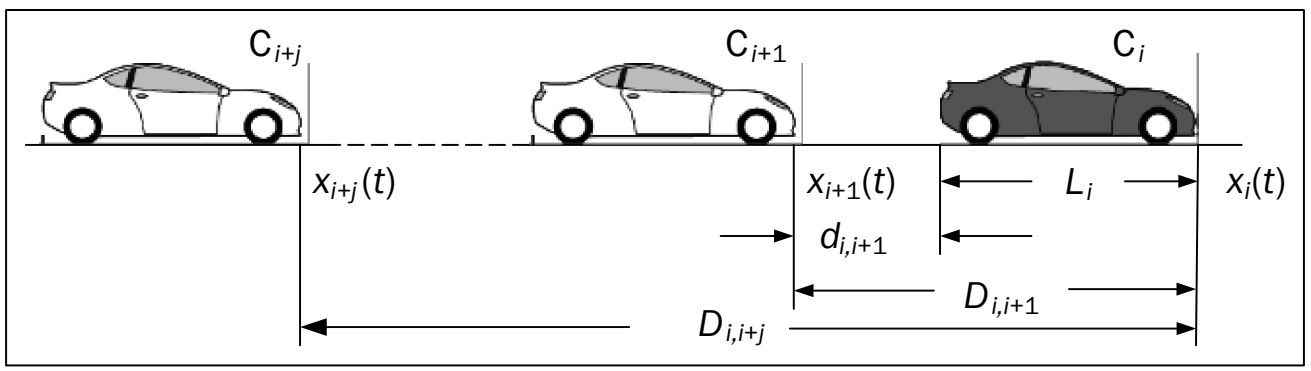

Figure 1 - Vehicle following model 


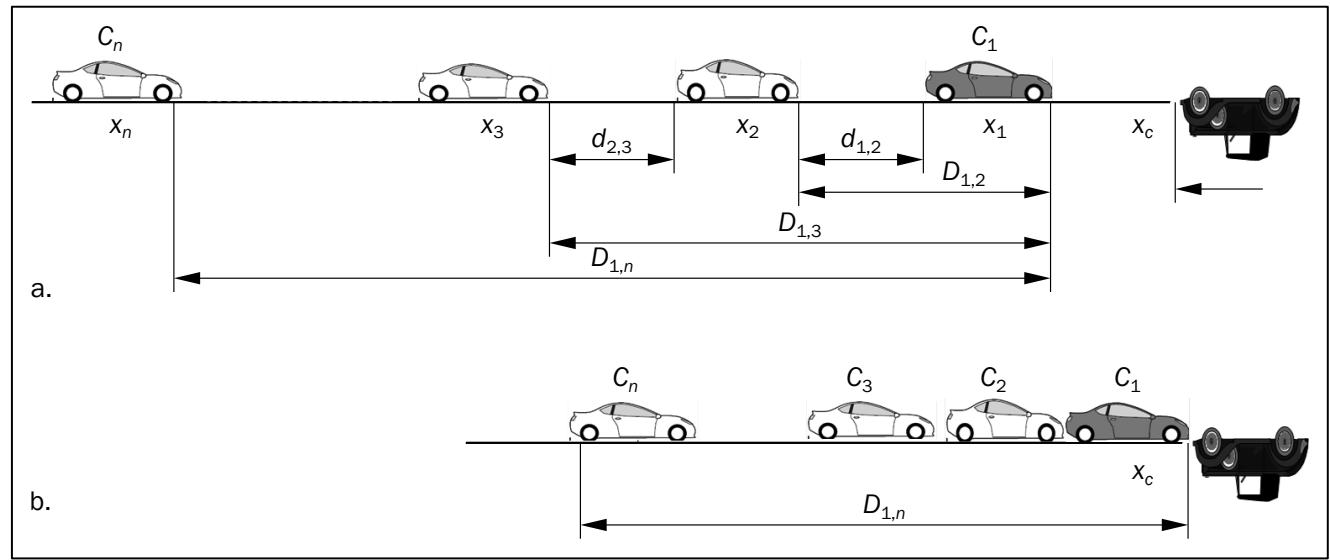

Figure 2 - Motorcade on freeway

upon LOS conditions, when the distances are small (up to $25 \mathrm{~m}$ ), is 0.84-0.91. When the distance between vehicles is $150 \mathrm{~m}$, the reliability of successful transmission of beacon falls down to 0.49-0.61.

In this paper, we confine ourselves strictly to the idealized model of V2V system; all EM transmissions are considered successful and their delays not exceeding $100 \mathrm{~ms}$.

\section{EMERGENCY BRAKING}

Suppose that under poor visibility conditions (fog or snow) on the road, a substantial obstacle that cannot be bypassed or avoided (Figure 2a) occurred. The position of this obstacle is $x_{c}$. The drivers having noticed this obstacle begin to stop and the vehicle queue stops, as shown in Figure $2 b$. In this situation, if a part of the vehicles collide, there may be other possible bad consequences.

Assume that a driver of the leading vehicle $C_{1}$ being in point $x_{1}\left(t_{0}\right)$ at time $t_{0}$ noticed an obstacle on the road. At this point, the rest of the way to the obstacle equals:

$$
d_{0,1}\left(t_{0}\right)=d_{0,1}=x_{c}-x_{1}\left(t_{0}\right) \text {. }
$$

Potentially possible braking distance for vehicle $C_{2}$ is longer (Figure 2a) and equals:

$d_{0,2}\left(t_{0}\right)=d_{0,2}=x_{c}-x_{2}\left(t_{0}\right)-L_{1}=d_{0,1}+d_{1,2}$.

Accordingly, the possible braking distance for vehicle $C_{j}$ is:

$d_{0, j}\left(t_{0}\right)=d_{0, j}=\sum_{k=1}^{j} d_{k-1, k}$.

These theoretically possible braking distances are established for the conditional moment $t_{0}$, i.e. the moment when a driver of the leading vehicle $C_{1}$ noticed an obstacle on the road. It is considered that a driver of the $j$-th vehicle could not see the obstacle directly, so they begin braking somewhat later - at moment $t_{b j}$, when they notice that the vehicle ahead begins braking suddenly or receive a warning signal through V2V system. Prior to moment $t_{b j}$, the initial velocity $v_{0}$ of all vehicles is the same. So, the stopping distance of the $j$-th vehicle decreases and becomes equal to:

$d_{j}\left(t_{b j}\right)=d_{0, j}\left(t_{0}\right)-v_{0}\left(t_{b j}-t_{0}\right)$.

As it may be seen, the said stopping distance depends on the location (position number) of the vehicle in the motorcade and on the real delay of the beginning of braking that, in its turn, depends on the chosen scenario - with or without VANET system.

\subsection{Time series of emergency stop of vehicles}

As mentioned above, the driver of the leading vehicle $C_{1}$ was able to see the obstacle at time $t_{0}$. The actual emergency braking begins a bit later, as each driver needs time to recognize an obstacle as hazard and to react to it. First stopping is initiated by the vehicle driver and is fully autonomous. The actual braking starts when the driver understands that it is necessary to stop at the moment:

$t_{b 1}=t_{0}+t_{r e}+t_{p r}$,

where $t_{r e}$ is time required to recognize the obstacle as a hazard; $t_{p r}$ is the pre-braking time, including driver's reaction and brake system response times (Equation 8). In this case, VANET equipment causes no influence.

The obstacle is not visible in advance to other drivers. Start of other $\left(C_{2}, C_{3}, \ldots\right)$ vehicles braking depends upon whether they are equipped with VANET or not. These two scenarios resulted in differing initial conditions for the emergency braking.

In the first scenario (without VANET), stopping conditions of vehicles $C_{2}, C_{3}, \ldots$ are identical to those of vehicle $C_{1}$. The driver of vehicle $C_{j}(j=2,3, \ldots)$ begins to stop only when they notice that vehicle $C_{j-1}$, which they follow suddenly stops (here assumed that the driver of vehicle $C_{j}$ can only see vehicle $C_{j-1}$ stop, but cannot see other vehicles ahead $-C_{j-2}, \ldots$ ) 
This results in braking time sequence, which further delays the vehicle braking time of the driver reaction time size:

$$
\begin{aligned}
& t_{b 1}=t_{0}+t_{r e 1}+t_{p r 1}, \\
& t_{b 2}=t_{b 1}+t_{r e 2}+t_{p r 2}, \\
& \ldots \ldots \ldots \ldots \ldots \\
& t_{b j}=t_{b j-1}+t_{r e j}+t_{p r j}= \\
& =t_{0}+\sum_{k=1}^{j}\left(t_{r e, k}+t_{p r, k}\right), j=2,3, \ldots, n,
\end{aligned}
$$

where $t_{r e j}+t_{p r j}$ is the total response time of the driver and the braking system of the $j$-th vehicle.

As can be seen, in this case, the start of braking time of $C_{j}$ vehicle increases with vehicle position number.

In the second scenario (with VANET), where the vehicles are equipped with radio communication system VANET, when vehicle $C_{1}$ starts suddenly stopping, at time $t_{b 1}^{V}=t_{0}^{V}+t_{r e 1}^{V}+t_{p r 1}^{V}$ vehicle $C_{1}$ sends the Emergency Message (EM).

Assume that drivers of vehicles $C_{2}, C_{3}, \ldots$ when they heard EM immediately start to stop. In this case, all drivers who heard the EM begin to stop practically at the same time. In this case, times required for drivers of vehicles $C_{2}, C_{3}, \ldots$ to recognize the obstacle as a hazard are replaced by EM transmission time. Drivers of the said vehicles respond to $E M$, not to the obstacle, so the driver's response time $\tau_{r}$ remains in the calculations. This results in the braking time sequence:

$$
\begin{aligned}
& t_{b 1}^{V}=t_{b 1}=t_{0}^{V}+t_{r e 1}^{V}+t_{p r 1}^{V}, \\
& t_{b 2}^{V}=t_{b 1}^{V}+t_{d 2}^{V}+t_{p r 2}^{V}, \\
& \ldots \ldots \ldots \ldots \ldots \ldots \ldots \\
& t_{b j}^{V}=t_{b 1}+t_{d j}^{v}+t_{p r j}^{V}, j=2,3, \ldots, n,
\end{aligned}
$$

where $t_{d j}^{V}$ is the EM transmission time to vehicle $C_{j}$.

Comparing the braking time sequences (18) and (19) it is found that VANET system can reduce the delay of applying the brakes in a motorcade at size:

$$
\begin{gathered}
\Delta t_{b j}^{v}=t_{b j}-t_{b j}^{v}=t_{0}+\sum_{k=1}^{j}\left(t_{r e, k}+t_{p r, k}\right)-\left(t_{b 1}^{v}+t_{d j}^{v}+t_{p r j}^{v}\right), \\
j=2,3, \ldots
\end{gathered}
$$

The stopping time of the first vehicle does not depend on the presence of VANET, so $t_{0}=t_{0}^{V}$ and $t_{b 1}=t_{b 1}^{V}$. Upon taking the said into account:

$\Delta t_{b j}^{v}=\sum_{k=2}^{j}\left(t_{r e, k}+t_{p r, k}\right)-t_{d j}^{v}-t_{p r j}^{v}, j=2,3, \ldots$

If $t_{r e}$ and $t_{p r}$ are the same for all vehicles of the motorcade, the installed $\mathrm{V} 2 \mathrm{~V}$ system may reduce the delay of the moment when vehicle $C_{j}$ of the motorcade begins stopping by the following value:

$$
\Delta t_{b j}^{V}=(j-1)\left(t_{r e}+t_{p r}\right)-t_{d j}^{V}-t_{p r j}^{v} \text {. }
$$

As seen, the installed VANET system eliminates the response time of the drivers and the brake systems of j- 1 vehicles.

\subsection{Actual distance to collision}

The actual possible distance of vehicle $C_{j}$ to collision is expressed as a sum of the distances between vehicles formed at moment $t_{b j}$, when vehicle $C_{j}$ begins braking. The actual distance to collision of the first vehicle $C_{1}$ depends only on the initial distance $d_{0,1}\left(t_{0}\right)$ at moment $t_{0}$ and the distance covered by the vehicle for the generalized reaction time of the driver and the vehicle $v_{0}\left(t_{r e 1}+t_{p r 1}\right)$, and equals:

$d_{1}\left(t_{b 1}\right)=d_{0,1}\left(t_{0}\right)-v_{0}\left(t_{r e 1}+t_{p r 1}\right)$.

The actual distance to collision of the second vehicle $C_{2}$ depends on the initial distances $d_{0,1}\left(t_{0}\right)$ and $d_{1,2}\left(t_{0}\right)$ and on the reaction time of the drivers of vehicle $C_{1}$ and vehicle $C_{2}$, respectively. However, the moment of beginning of braking by vehicle $C_{2}$ depends on the presence of V2V system in the first vehicle. So, if the first or the second scenario is chosen, each case should be analyzed individually.

In the first scenario, the actual distance to collision for the second vehicle is:

$d_{2}\left(t_{b 2}\right)=d_{0,1}\left(t_{0}\right)+d_{1,2}\left(t_{0}\right)-v_{0}\left(t_{r e 1}+t_{r e 2}+t_{p r 1}+t_{p r 2}\right)$.

Similarly, the actual distance to collision for the $j$-th vehicle is expressed as:

$d_{j}\left(t_{b j}\right)=\sum_{k=1}^{j} d_{k-1, k}\left(t_{0}\right)-v_{0} \sum_{k=1}^{j}\left(t_{r e, k}+t_{p r, k}\right), j=2,3, \ldots$

where $t_{r e j}+t_{p r j}$ is the total response time of the driver and the brake system of the $j$-th vehicle.

Let's suppose that all vehicles keep the safe distance $d_{k-1, k}\left(t_{0}\right)=v_{0} \cdot \theta_{s}$, that the lengths of the vehicles are the same and equal to $L$, their pre-braking times are the same and the reaction times of all drivers are the same as well. A simple expression of the actual distance to collision is found:

$$
\begin{aligned}
d_{j}\left(t_{b j}\right) & =d_{0,1}\left(t_{0}\right)+(j-1) \cdot v_{0} \cdot \theta_{s}-j \cdot v_{0}\left(t_{r e}+t_{p r}\right), \\
j & =2,3, \ldots
\end{aligned}
$$

In the second scenario when the vehicles are equipped with radio communication system VANET, the actual distances to collision shall be expressed as follows:

$$
\begin{aligned}
d_{1}^{v}\left(t_{b 1}\right) & =d_{0,1}\left(t_{0}\right)-v_{0}\left(t_{r e 1}+t_{p r 1}\right), \\
d_{2}^{v}\left(t_{b 2}\right) & =d_{0,1}\left(t_{0}\right)+d_{1,2}\left(t_{0}\right)-v_{0}\left(t_{r e 1}+t_{p r 1}+t_{d 2}^{v}+t_{p r 2}^{v}\right), \\
d_{j}^{v}\left(t_{b j}\right) & =\sum_{k=1}^{j} d_{k-1, k}\left(t_{0}\right)-v_{0}\left(t_{r e 1}+t_{p r 1}+t_{d j}^{v}+t_{p r j}^{v}\right), \\
j & =2,3, \ldots
\end{aligned}
$$

It is considered that pre-braking times are the same for both scenarios, i.e. $t_{p r j}=t_{p r j}^{V}$. When all vehicles keep the safe distance $d_{k-1, k}\left(t_{0}\right)=v_{0} \cdot \theta_{s}$, the lengths of the vehicles are the same and equal to $L$, their pre-braking times are the same and the reaction times of all drivers are the same, the actual distance to collision is found from the following expression: 


$$
\begin{aligned}
d_{j}^{V}\left(t_{b j}\right) & =d_{0,1}\left(t_{0}\right)+(j-1) \cdot v_{0} \cdot \theta_{s}-v_{0}\left(t_{r e}+2 t_{p r}+t_{d j}^{V}\right), \\
j & =2,3, \ldots
\end{aligned}
$$

On comparing the scenario without VANET and the scenario with VANET, the differences of the actual distances to collision become evident:

$$
\begin{aligned}
& \Delta d_{1}^{V}\left(t_{b 1}\right)=d_{1}^{V}\left(t_{b 1}\right)-d_{1}\left(t_{b 1}\right)=0, \\
& \Delta d_{2}^{V}\left(t_{b 2}\right)=d_{2}^{V}\left(t_{b 2}\right)-d_{2}\left(t_{b 2}\right)=v_{0}\left(t_{r e 2}-t_{d 2}^{V}\right), \\
& \ldots \ldots \ldots \ldots \ldots \ldots \\
& \begin{aligned}
\Delta d_{j}^{V}\left(t_{b j}\right) & =d_{j}^{V}\left(t_{b j}\right)-d_{j}\left(t_{b j}\right)= \\
\quad & v_{0}\left(\sum_{k=2}^{j} t_{r e, k}+\sum_{k=2}^{j-1} t_{p r, k}-t_{d j}^{v}\right), j \geq 3
\end{aligned}
\end{aligned}
$$

If we suppose that the reaction times of all drivers are the same, the following expression for the difference of the actual distances to collision will be obtained:

$$
\Delta d_{j}^{V}\left(t_{b j}\right)=v_{0}\left[(j-1) t_{r e}+(j-2) t_{p r}-t_{d j}^{V}\right] \text {. }
$$

This equation could be changed as follows:

$\Delta d_{j}^{V}\left(t_{b j}\right)=v_{0}\left[j\left(t_{r e}+t_{p r}\right)-\left(t_{d j}^{V}+t_{r e}+2 t_{p r}\right)\right]$.

It may be seen from the above that with the growing velocity and the position number of vehicles, the difference of the actual distances to collision grows linearly.

As seen in the second scenario, when the vehicles are equipped with radio communication system VANET, the difference of the actual distances to collision grows with the growing of the position number of a vehicle in the motorcade.

\section{CRASH AVOIDANCE CONDITIONS}

Vehicle $C_{j}$ will avoid a collision, if its residual distance $d_{j}\left(t_{b j}\right)$ equals to or exceeds its physical stopping distance $\Delta X$ expressed by formula (6):

$d_{j}\left(t_{b j}\right) \geq \Delta X_{s}=\frac{v_{0}^{2}}{2 g \mu_{e} \chi}$.

Upon the conditions of the first scenario, the residual distance $d_{j}\left(t_{b j}\right)$ is described by expression (25). When pre-braking times of all vehicles are the same and the reaction times of all drivers are the same as well, the following inequation is obtained:

$$
\begin{gathered}
d_{0,1}\left(t_{0}\right)+(j-1) \cdot v_{0} \cdot \theta_{s}-j \cdot v_{0}\left(t_{r e}+t_{p r}\right) \geq \frac{v_{0}^{2}}{2 g \mu_{e} \chi}, \\
j=2,3, \ldots .
\end{gathered}
$$

From the inequation, the sought natural number $j$ that conforms to the number of the vehicle in the motorcade is found:

$j \geq \frac{\frac{v_{0}^{2}}{2 g \mu_{e} \varkappa}+v_{0} \cdot \theta_{s}-d_{0,1}\left(t_{0}\right)}{v_{0}\left(\theta_{s}-t_{r e}-t_{p r}\right)}$.

Upon the conditions of the second scenario, the residual distance $d_{j}\left(t_{b j}\right)$ is described by formula (28); on using it, an analogous inequation is obtained:

$$
d_{0,1}\left(t_{0}\right)+\left(j^{v}-1\right) \cdot v_{0} \cdot \theta_{s}-v_{0}\left(t_{r e}+2 t_{p r}+t_{d j}^{v}\right) \geq \frac{v_{0}^{2}}{2 g \mu_{e} \varkappa},
$$

Then $j$ is expressed as follows:

$$
j^{v} \geq \frac{\frac{v_{0}^{2}}{2 g \mu_{e} \varkappa}+v_{0} \theta_{s}-d_{0,1}\left(t_{0}\right)+v_{0}\left(t_{r e}+2 t_{p r}+t_{d j}^{v}\right)}{v_{0} \theta_{s}} \text {. }
$$

All vehicles with the position numbers $j$ in the motorcade that satisfy the conditions of equations (34) or (36) will avoid a crash. The lowest of these numbers hereafter are marked $J_{s}$ and $J_{s}^{V}$ respectively. Several examples are shown in Table 1.

Table 1 - The lowest position number of vehicle in motorcade avoiding the crash

\begin{tabular}{||c|c|c|c|c|c|c|c||}
\hline $\begin{array}{c}V_{0}, \\
\mathrm{~km} / \mathrm{h}\end{array}$ & 50 & 60 & 70 & 80 & 90 & 100 & Conditions \\
\hline \hline \multirow{3}{*}{$J_{s}$} & 3 & 4 & 5 & 5 & 6 & 6 & snowy, $a_{i}=2.5 \mathrm{~m} / \mathrm{s}^{2}$ \\
\cline { 2 - 9 } & 2 & 2 & 3 & 3 & 3 & 4 & wet, $a_{i}=5.5 \mathrm{~m} / \mathrm{s}^{2}$ \\
\cline { 2 - 9 } & 2 & 2 & 2 & 3 & 3 & 3 & dry, $a_{i}=7.5 \mathrm{~m} / \mathrm{s}^{2}$ \\
\hline \multirow{3}{*}{$J_{s}^{v}$} & 2 & 2 & 2 & 3 & 3 & 3 & snowy, $a_{i}=2.5 \mathrm{~m} / \mathrm{s}^{2}$ \\
\cline { 2 - 9 } & 2 & 3 & 3 & 3 & 3 & 3 & wet, $a_{i}=5.5 \mathrm{~m} / \mathrm{s}^{2}$ \\
\cline { 2 - 9 } & 2 & 2 & 3 & 3 & 3 & 3 & dry, $a_{i}=7.5 \mathrm{~m} / \mathrm{s}^{2}$ \\
\hline
\end{tabular}

\subsection{Time to collision}

Vehicle $C_{1}$ may stop before encountering an obstacle, if the distance to the obstacle $d_{0} \geq D_{s}$ is no less than stopping distance given by (9). If the distance to the obstacle $d_{0}$ is less than the stopping distance ( $d_{0}<D_{s}$ ), an accident will occur, i.e. the vehicle will encounter an obstacle. The time to collision $T_{C 1}$ of vehicle $C_{1}$ is calculated using equation (4) and is:

$$
v_{0} T_{c 1}-\frac{g \mu_{e} \varkappa T_{c 1}^{2}}{2}=d_{1}\left(t_{b 1}\right) \text {. }
$$

From this equation, time to collision is calculated:

$T_{c 1}=\frac{v_{0}-\sqrt{v_{0}^{2}-2 g \mu_{e} \varkappa d_{1}\left(t_{b 1}\right)}}{g \mu_{e} \varkappa}$.

Negative value under the root means that the distance between vehicles is larger than necessary to avoid collision.

For other vehicles, time to collision is calculated according to formula (38) where $d_{1}\left(t_{b 1}\right)$ is replaced by $d_{j}\left(t_{b j}\right)$ :

$$
T_{c j}=\frac{v_{0}-\sqrt{v_{0}^{2}-2 g \mu_{e} \varkappa d_{j}\left(t_{b j}\right)}}{g \mu_{e} \varkappa}, j=2,3, \ldots<J_{s} .
$$

On analyzing time to collision of vehicle $C_{j}$ in the first scenario, variable $d_{j}\left(t_{b j}\right)$ is described by expression (25) and on analyzing its time to collision in the second scenario, the said variable is described by formula (28).

When pre-braking times of all vehicles are the same and the reaction times of all drivers are the 
same as well, time to collision of vehicle $C_{j}$ in the first scenario is:

$$
T_{c j}=\frac{v_{0}-\sqrt{v_{0}^{2}-2 g \mu_{\mathrm{e}} \chi\left[d_{0,1}\left(t_{0}\right)+(j-1) \cdot v_{0} \cdot \theta_{s}-j \cdot v_{0}\left(t_{r e}+t_{p r}\right)\right]}}{g \mu_{\mathrm{e}} \varkappa},
$$

In the second scenario, time to collision of vehicle $C_{j}$ is:

$$
\begin{gathered}
T_{c j}^{V}=\frac{v_{0}-\sqrt{v_{0}^{2}-2 g \mu_{e} \chi\left[d_{0,1}\left(t_{0}\right)+(j-1) \cdot v_{0} \cdot \theta_{s}-v_{0}\left(t_{r e}+2 t_{p r}+t_{d j}^{v}\right)\right]}}{g \mu_{e} \chi}, \\
j=2,3, \ldots<J_{s}^{v}
\end{gathered}
$$

Time to collision gaining upon different road conditions is shown in Figure 3. It is a graphical image of the difference between the values calculated according to formulas (40) and (41):

$\Delta T_{c j}=T_{c j}^{V}-T_{c j}, j=2,3, \ldots$

where $d_{0}=20 \mathrm{~m}, \theta=2.0 \mathrm{~m}, L=5 \mathrm{~m}, t_{r e}=0.4 \mathrm{~s}$, $t_{p r}=0.75 \mathrm{~s}, t_{d j}^{v}=0.13 \mathrm{~s}$. Zeros in Figure 3 means that the collision is avoided and growing columns mean the increasing time to collision because of the VANET system effect.

The key effect of the communication system between vehicles in a motorcade is caused by elimination of the time for recognizing an obstacle by a driver. In this case, the driver needs no time to recognize traffic danger, so onlytheir ordinary reaction to emergency signal (EM) remains. So, the effect of VANET system is higher when the time for recognizing an obstacle by a driver is longer, for example, in conditions of poor visibility. The system is particularly efficient in the traffic scenarios where high velocities and monotonous driving conditions prevail. In such cases, drivers are not ready to meet unexpected obstacles and their reaction to dangerous traffic situations is delayed.

In Figure 3, specific traffic conditions are shown. In the case shown in Figure 3a, when the pavement is slippery, the maximum differences of times to collision are obtained. If the initial velocity is $90-130 \mathrm{~km} / \mathrm{h}$, VANET system enables the fourth and the fifth vehicles of the motorcade to gain 5.4-6.8 s of the time to collision. Upon the condition of wet road (Figure 3b), a higher gain in the time to collision was found for the third vehicle of the motorcade, when the velocity starts from $110 \mathrm{~km} / \mathrm{h}$.

\subsection{Emergency residual velocity}

Emergency residual velocity characterizes the vehicle speed or amount of energy on the moment of the vehicle collision. At the end of period $T_{C 1}$, emergency residual velocity is calculated according to formula (17) and is equal to:

$$
v_{e c 1}=v_{0}-g_{0} \mu_{e} \varkappa T_{c 1} \text {. }
$$

The obtained expression of emergency residual velocity $v_{e c 1}$ is:

$v_{e c 1}=\sqrt{v_{0}^{2}-2 g \mu_{e} \varkappa d_{j}\left(t_{b j}\right)}$.
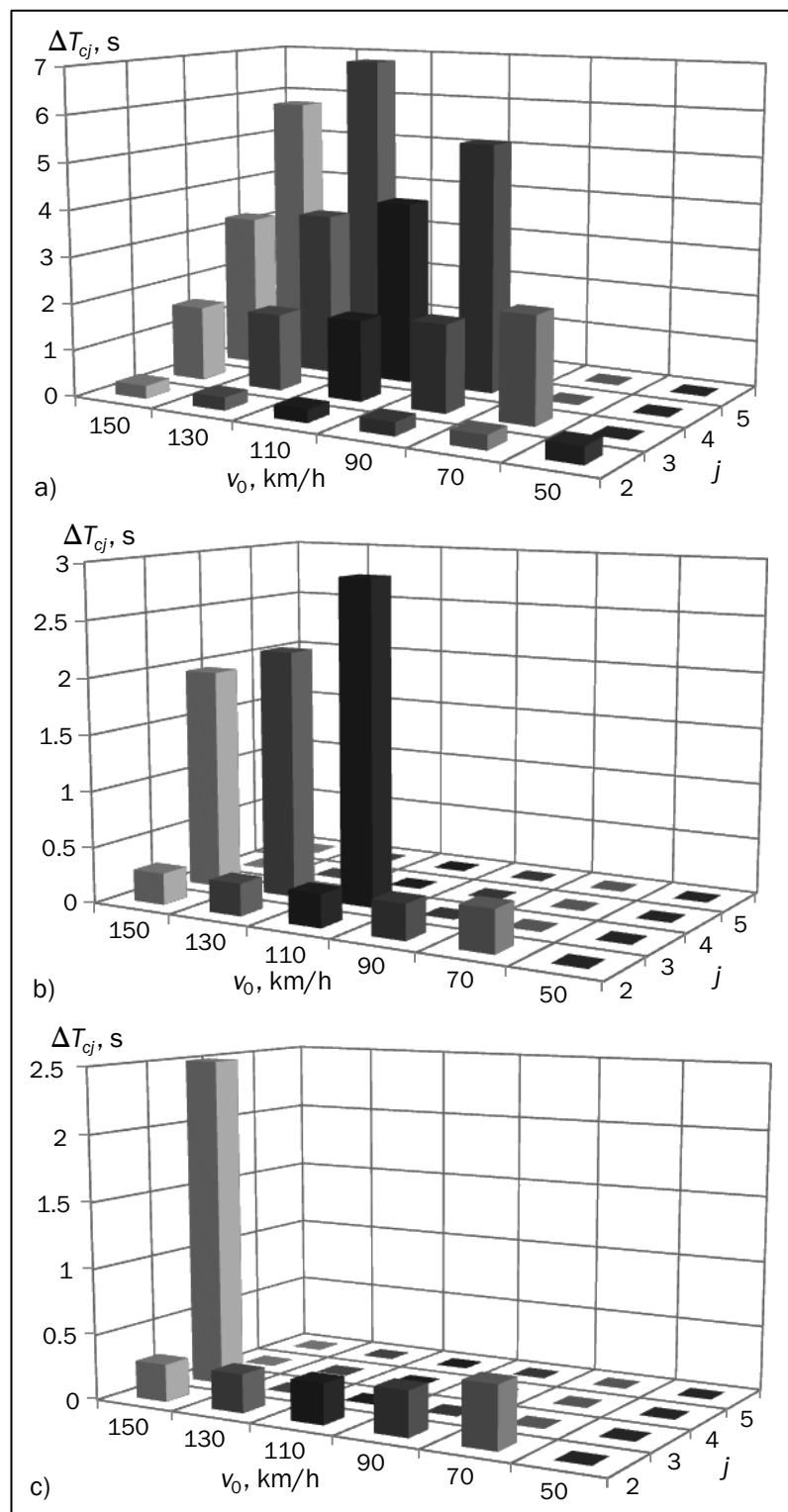

Figure 3 - Gaining of time $\Delta T_{c j}$ to collision affected by VANET system: a) snowy, $\left.a_{i}=g \mu_{i} \chi=2.5 \mathrm{~m} / \mathrm{s}^{2}, b\right)$ wet, $\left.a_{i}=g \mu_{i} \varkappa=5.5 \mathrm{~m} / \mathrm{s}^{2}, c\right) d r y, a_{i}=g \mu_{i} \varkappa=7.5 \mathrm{~m} / \mathrm{s}^{2}$

Analogously, the emergency residual velocity of vehicle $C_{j}$ is calculated according to formula (44), where values of $d_{0}$ are replaced by values $d_{j}\left(t_{b j}\right)$ calculated according to formulas (25) and (27), respectively. When pre-braking times of all vehicles are the same and the reaction times of all drivers are the same as well, we obtain:

$$
\begin{aligned}
v_{e c j}= & \sqrt{v_{0}^{2}-2 g \mu_{e} \chi\left[d_{0,1}\left(t_{0}\right)+(j-1) v_{0} \cdot \theta_{s}-j \cdot v_{0}\left(t_{r e}+t_{p r}\right)\right]}, \\
& j=2,3, \ldots
\end{aligned}
$$

$v_{\mathrm{ecj}}^{v}=\sqrt{v_{0}^{2}-2 g \mu_{\mathrm{e}} \varkappa\left[d_{0,1}\left(t_{0}\right)+(j-1) v_{0} \cdot \theta_{s}-v_{0}\left(t_{r e}+2 t_{p r}+t_{d j}^{v}\right)\right]}$,

$$
j=2,3, \ldots
$$

Figure 4 shows the emergency residual velocity of specific vehicle of the motorcade without and with VANET system. The initial driving conditions are chosen the same as in the cases shown in Figure 3 above. 

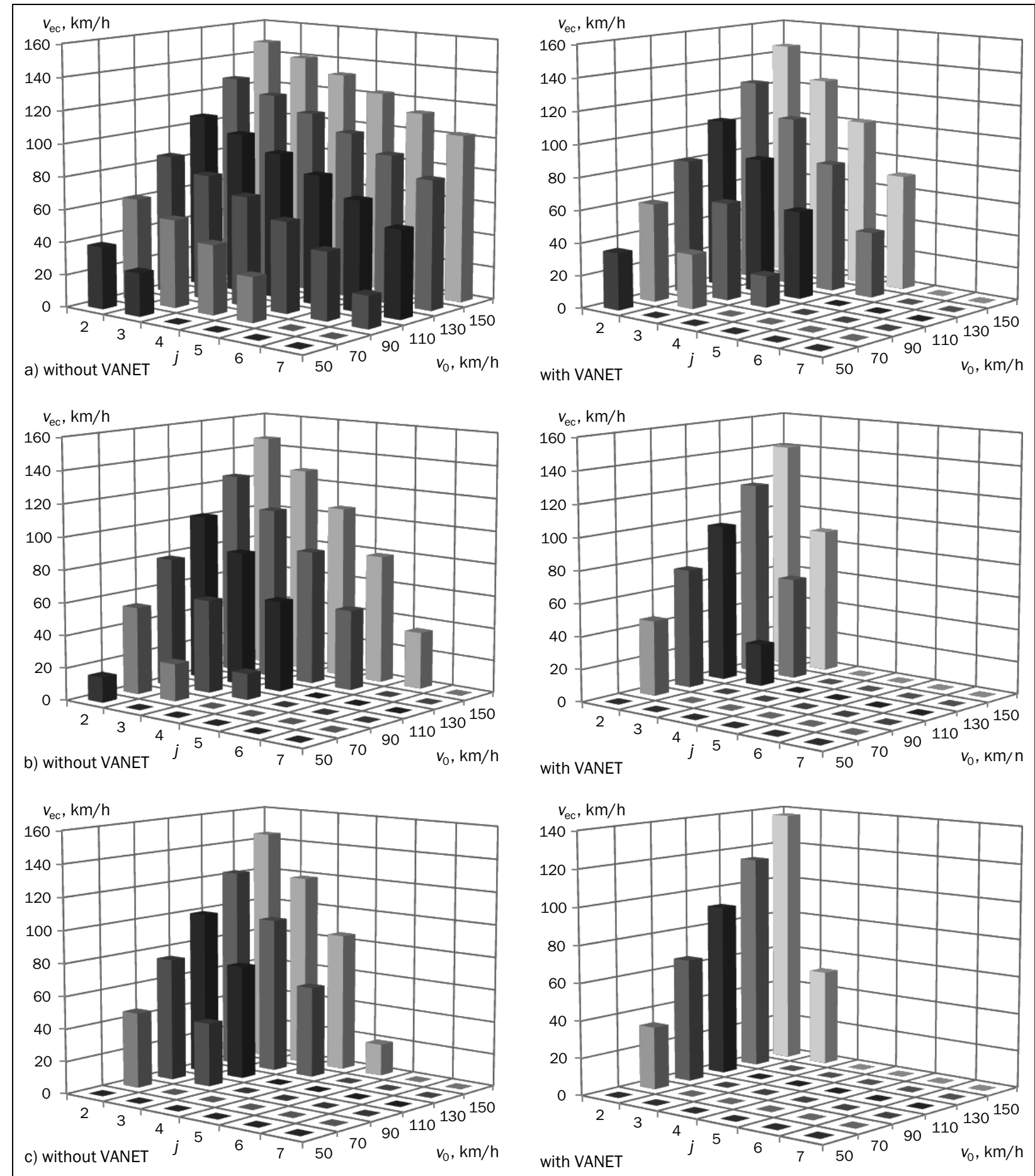

Figure 4 - Residual velocity at various $v_{0}$ : a) snowy, $a_{i}=g \mu_{i} \chi=2.5 \mathrm{~m} / \mathrm{s}^{2}$,

b) wet, $\left.a_{i}=g \mu_{i} \varkappa=5.5 \mathrm{~m} / \mathrm{s}^{2}, c\right) d r y, a_{i}=g \mu_{i} \varkappa=7.5 \mathrm{~m} / \mathrm{s}^{2}$

On comparing the graphs for cases without and with VANET system, an evident effect of the communication can be observed. For snowy road conditions (Figure 4a), only four cases of reaching the obstacle by the vehicle at the velocity of $0 \mathrm{~km} / \mathrm{h}$, i.e. avoiding collision, are shown. Under the same conditions, the sixth and the seventh vehicles of the motorcade equipped with VANET system will reach the obstacle safely in all cases under analysis. In dry asphalt conditions, a danger (in the presence of the communication system) was established only for the second vehicle of the motorcade; it also exists for the third vehicle when the velocity exceeds $150 \mathrm{~km} / \mathrm{h}$.

\section{CONCLUSION}

The paper examines possible influence of VANET system on collisions of a motorcade. After an analysis 
of the cases of distance to possible collision and time to possible collision as well as the dependence of the residual velocity on the position number of the vehicle in a motorcade and the initial driving conditions, the conclusions were formulated.

In modern highway running, many vehicles are involved, the distances between them are quite small, and in the event of unexpected obstacles, the key factor that prevents severe crashes is an early warning of an obstacle. VANET system here can be quite effective.

Every vehicle will escape a possible collision if the warning message of an obstacle on the road reaches the driver early enough when the rest of the road to obstacle is sufficient for the vehicle to stop. This rule applies to any vehicle in a motorcade, regardless of the local position in the queue to the obstacle.

When the residual distance to the obstacle is less than the stopping distance, the vehicle cannot avoid collision, but the consequences of collision may be mitigated. The crucial aim of configuration of the communication between vehicles is elimination of the time needed to recognize an obstacle as a hazard (that depends on the driver) from the total stopping time. The shorter duration of emergency message transmission, the shorter is the pre-braking time. The physiological reaction of the driver to EM remains.

On comparing the differences of the times to collision in the presence and absence of the communication system, the maximum gain was observed upon the conditions of poor adherence with the road. The time gain of the second vehicle of the motorcade is small, as compared with the gains of the successive vehicles where the introduction of VANET system may cause an additional gain of $6.8 \mathrm{~s}$. The difference of the residual velocities before collision clearly characterizes the potential damage that may be caused by a possible traffic event. If the communication system is introduced in vehicles and if all drivers keep a safe distance, even the second or third vehicle of the motorcade will absolutely avoid a possible collision. However, VANET system does not guarantee absolute road traffic safety. Developing safety systems of road traffic the obstacles identification radars and other devices should be integrated together with VANET system.

Prof. habil. dr. ALGIMANTAS KAJACKAS

E-mail: algimantas.kajackas@vgtu.It

Elektronikos fakultetas

Telekomunikaciju inžinerijos katedra

Vilniaus Gedimino technikos universitetas

Naugarduko g. 41, LT-03227 Vilnius, Lietuva

Dokt. VIDAS ŽURAULIS

E-mail: vidas.zuraulis@vgtu.It

Saugaus eismo laboratorija

Prof. dr. EDGAR SOKOLOVSKIJ

E-mail: edgar.sokolovskij@vgtu.It

Transporto inžinerijos fakultetas

Automobiliu transporto katedra
Vilniaus Gedimino technikos universitetas

J. Basanavičiaus g. 28B, LT-03224 Vilnius, Lietuva

\section{SANTRAUKA}

\section{TRANSPORTO PRIEMONIU KOMUNIKACIJOS SISTEMOS ITAKOS EISMO SRAUTU JUDE்JIMUI AVARINĖMIS SITUACIJOMIS ANALIZE்}

Šis straipsnis yra paremtas avarinejje situacijoje kolona judančiu transporto priemoniu komunikacijos sistemos analize. Analize siekiama atsakyti i klausimą kada, kokiomis salygomis transporto priemoniu tarpusavio komunikacijos sistemos siunčiamas avarinis signalas pasiekia gavejją ir padeda apsisaugoti nuo tokiu eismo ivykiu, kaip masiniai susidūrimai. Pagrindiniais automobilio stabdymo principais paremtas skaičiavimo modelis leidžia nustatyti laiką iki galimo susidūrimo ir automobilio likutini greitj. Skaičiavimuose priimamos vidutinès vairuotojo reakcijos laiko reikšmès ir laikoma, kad avarinis signalas siunčiamas be trikdžių. Parinkus skirtingas kelio ir važiavimo sąlygas nustatoma, kuri kolonos transporto priemonè ekstremalaus stabdymo metu suspès sustoti iki galimos kliūties. Pateikiamas transporto priemoniu su komunikacijos sistema ir be jos palyginimas.

\section{RAKTINIAI ŽODŽIAI}

transporto priemoniu komunikacija; stabdymas; avarinis sustojimas; laikas iki susidūrimo; likutinis greitis;

\section{REFERENCES}

[1] Prentkovskis O, Sokolovskij E, Bartulis V. Investigating traffic accidents: a collision of two motor vehicles. Transport. 2010;25(2):105-115.

[2] Sokolovskij E, Prentkovskis O. Investigating traffic accidents: the interaction between a motor vehicle and a pedestrian. Transport. 2013;28(3):302-312.

[3] Žuraulis V, Sokolovskij E, Matijošius J. The opportunities for establishing the critical speed of the vehicle on research in its lateral dynamics. Eksploatacja i Niezawodnosc - Maintenance and Reliability. 2013;15(4):312-318.

[4] Čygas D, Mučinis D, Sivilevičius H, Abukauskas N. Dependence of the recycled asphalt mixture psychical and mechanical properties on the grade and amount of rejuvenating bitumen. The Baltic Journal of Road and Bridge Engineering. 2011;6(2):124-134.

[5] Sivilevičius $\mathrm{H}$. Modelling the interaction of transport system elements. Transport. 2011;26(1):20-34.

[6] Chen Ch, Liu L, Du X, Wei X, Pei Ch. Available connectivity analysis under free flow state in VANETs. EURASIP Journal on Wireless Communications and Networking. 2012:270.

[7] Zeadally Sh, Hunt R, Chen Y, Irwin A, Hassan A. Vehicular ad hoc networks VANETS: status, results, and challenges. Telecommunication Systems. 2012;50(4):217241.

[8] Sichitiu ML, Raleigh NC, Kihl M. Inter-vehicle communication systems: a survey. Communications Surveys \& Tutorials, IEEE. 2008;10(2):88-105 
[9] Hartenstein H, Laberteaux K. A tutorial survey on vehicular ad hoc networks. Communications Magazine, IEEE. 2008;46(6):71-164.

[10] Milanes V, Onieva E, Perez J, Simo J, Gonzalez C, Pedro T. Making Transport Safer: V2V-based Automated Emergency Braking System. Transport. 2011;26(3):291302.

[11] Ghasemi A, Kazemi R, Azadi SH. Directional control of a platoon of vehicles for comfort specification by considering parasitic time delays and lags. Promet Traffic\&Transportation. 2013;25(5):413-420.

[12] IEEE Standards Association. IEEE 802.11p-2010: Wireless LAN Medium Access Control (MAC) and Physical Layer (PHY) Specifications Amendment 6: Wireless Access in Vehicular Environments; 2010

[13] IEEE Standards Association, IEEE 1609 Family of Standards, IEEE Standard for Wireless Access in Vehicular Environments (WAVE), IEEE Std1609.2/.3/.4; 20102012.

[14] Djahel S, Ghamri-Doudane Y. A Robust Congestion Control Scheme for Fast and Reliable Dissemination of Safety Messages in VANETs. IEEE Wireless Com- munications and Networking Conference. 2012;22642269.

[15] Yang X, Liu J, Zhao F, Vaidya NF. A vehicle-to-vehicle communication protocol for cooperative collision warning. Proceedings of the First Annual International Conference on MOBIQUITOUS, 2004 Aug 22-26; Boston, MA. p. 114-123.

[16] Sokolovskij E. Experimental investigation of the braking process of automobiles. Transport. 2005;20(3):9195.

[17] Levulytè L, Žuraulis V, Sokolovskij E. The research of dynamic characteristics of a vehicle driving over road roughness. Eksploatacja i Niezawodnosc - Maintenance and Reliability. 2014;16(4):518-525.

[18] Riener KZ, Zia K, Ferscha A, Beltran CR, Minguez Rubio JJ. Traffic flow harmonization in expressway merging. Personal and Ubiquitous Computing. 2013 Mar;17(3):519-532.

[19] Martelli F, Renda ME, Santi P. Measuring IEEE 802.11p Performance for Active Safety Applications in Cooperative Vehicular Systems. VTC Spring, p. 1-5. IEEE; 2011. 